\title{
Short-term retention of temporal and spatial order
}

\author{
ALICE F. HEALY \\ The Rockefeller University, New York, New York 10021
}

\begin{abstract}
Retention of temporal and spatial order information were compared in a short-term recall situation where only order information was to be learned. Concave-upward bow-shaped serial position functions were found for temporal but not spatial positions, whether subjects recalled the temporal or the spatial order of the items. Retention of temporal order was superior to retention of spatial order. However, spatial and temporal order recall should be further compared with a design which eliminates an asymmetry present in this and previous studies.
\end{abstract}

A characteristic finding of short-term memory studies is the concave-upward bow-shaped serial position function: items at the beginning and end of an ordered list are recalled better than items in the middle. These bow-shaped functions are found even with short lists that are recalled after several seconds of intervening activity under conditions where rehearsal is precluded (e.g., Bjork \& Healy, 1974). The usual explanations for such findings -a rapidly decaying sensory store responsible for recency and selective rehearsal responsible for primacy-cannot be invoked in these situations. Rather, the bow-shaped curves seem to be due to some process intrinsically involved in the recall of order information. This notion is supported by the observation that the bowed curves are found when only order information is to be recalled but not when only item information is to be recalled (Healy, in press).

Estes (1972) has proposed a model, referred to here as the "synchrony model," which accounts for these functions solely in terms of temporal factors. According to this model, the temporal order of the items is preserved automatically via a reverberatory loop mechanism by which the representations of successively displayed items are reactivated at successive instants in time. This model implies that the bowed functions would not be observed with spatial rather than temporal positions in a situation where the temporal and spatial positions of items are varied independently. In contrast, the bowed curves would be expected for temporal positions even when the subject is to recall the spatial order of the items. The synchrony model further implies that the recall of temporal order information would be superior to the recall of spatial order information since temporal information would be registered automatically, whereas the retention of spatial information would be mediated by temporal factors.

The present experiment seeks to test these predictions

This paper is sponsored by W. K. Estes, who takes full editorial responsibility for its contents. This article is based on part of a doctoral dissertation submitted to The Rockefeller University. The research was supported by PHS Grants GM01789 and GM16735 to The Rockefeller University. Alice F. Healy is now at Yale University, New Haven, Connecticut 06520 . by comparing the retention of temporal and spatial order information in a short-term recall situation analogous to that described by Healy (in press) where only order information is to be retained. The temporal and spatial orders of the items are independently varied in a manner similar to that of several previous studies (e.g., Lundberg \& Book, 1969; Mandler \& Anderson, 1971; Murdock, 1969; Slamecka, 1967).

\section{METHOD}

\section{Subjects}

The subjects were 16 male and female young adults who were recruited by advertisements in a local newspaper and paid at the rate of $\$ 2.00$ per hour. There were two conditions with eight subjects in each condition.

\section{Apparatus}

An Iconix Bina-view display device, operated by means of a Digitronics paper tape reader, was used for the visual presentation of the stimuli. The Bina-view screen included four cells arranged in a horizontal linear array. These four cells defined four different spatial positions, numbered consecutively from left to right. Three clocks were included in the system to time the stimulus duration at $400 \mathrm{msec}$.per item, the intertrial interval at $16 \mathrm{sec}$; and the interstimulus interval at approximately $2 \mathrm{msec}$. Each character was approximately $3.5 \mathrm{~cm}$ high and $2.2 \mathrm{~cm}$ wide.

\section{Design and Materials}

A different 72-trial experimental sequence was prepared for each subject. A trial consisted of a four-consonant stimulus followed by a retention interval including either zero, four, or twelve intervening digits.

On half of the 72 trials, the subject was to recall the temporal order of the consonants and on the other half he was to recall the spatial order of the consonants. The presentation order of the trials was quasirandom with the constraint that in every block of 12 trials there were four instances of each of the three retention intervals, two of which involved spatial order recall and two temporal order recall.

The four consonants in a trial were presented successively, each consonant in a different one of the four cells of the screen, no consonant appearing in the same temporal and spatial positions on a trial. In this way the temporal and spatial orders of the consonants were varied independently. As each consonant was displayed in one of the four cells, the other three cells were left blank. Each of the digits in the retention interval, however, was displayed simultaneously in all four cells of the screen.

The same four consonants appeared on each experimental trial 
Table 1

Percentages of Correct Responses

\begin{tabular}{|c|c|c|c|c|c|c|c|c|}
\hline \multirow{2}{*}{$\begin{array}{l}\text { Recall } \\
\text { Order }\end{array}$} & \multicolumn{4}{|c|}{ Temporal Position } & \multicolumn{4}{|c|}{ Spatial Position } \\
\hline & 1 & 2 & 3 & 4 & 1 & 2 & 3 & 4 \\
\hline $\begin{array}{l}\text { Temporal } \\
\text { Spatial }\end{array}$ & $\begin{array}{l}81 \\
68\end{array}$ & $\begin{array}{l}68 \\
54\end{array}$ & $\begin{array}{l}73 \\
55\end{array}$ & $\begin{array}{l}81 \\
60\end{array}$ & $\begin{array}{l}72 \\
57\end{array}$ & $\begin{array}{l}79 \\
63\end{array}$ & $\begin{array}{l}78 \\
61\end{array}$ & $\begin{array}{l}74 \\
57\end{array}$ \\
\hline
\end{tabular}

of a given subject's session. Each of the 24 permutations of the four letters appeared once at each of the three retention intervals as the spatial ordering of the consonants, and once at each of the three retention intervals as the temporal ordering of the consonants. In exactly one of these cases at each retention interval, a given permutation represented the to-be-remembered order.

The order of the consonants, either temporal or spatial, that was to be recalled was cued either two seconds before the presentation of the consonants with a reminder immediately after the last digit (precue condition) or only immediately following the last digit (postcue condition). The cue consisted of the simultaneous presentation of the vowel I (for temporal order) or 0 (for spatial order) in all four cells of the screen. In the postcue condition the position of the precue was filled by a redundant vowel $\mathrm{U}$.

The intervening digits shown on each trial were randomly selected from the digits 1 to 9 with the constraint that no digit immediately succeed itself. The same digits were shown to all subjects; only the consonants differed across subjects.

The consonants were drawn from a population of eight: BPFSKMHL. Four subjects were shown BKFH; four were shown PMSL; four were shown BKPM; and four were shown FHSL. The four subjects shown a given set of letters included two subjects from each of the two conditions who saw identical displays except that for every trial the spatial order of the consonants shown to one subject was the temporal order shown to the other subject and vice versa. In addition, when temporal order was cued for one subject, spatial order was cued for the other.

Different permutations of the letters $A B C D$ were shown on the six practice trials. There were two practice trials at each of the three retention intervals, one cued for temporal order recall and one for spatial.

\section{Procedure}

Subjects were tested individually in hour-long sessions. Each subject was instructed to shadow, or read aloud, each item as it appeared on the screen. At the end of the sequence of items, the screen became blank and the subject was given $16 \mathrm{sec}$ to write down the four consonants in their proper order on a $3 \times 5$ card on which four boxes had been printed.

At the start of the experiment the subject was given full information concerning the four consonants that would be presented in varying orders during his session, followed by six practice trials.

\section{RESULTS}

Table 1 summarizes the present results in terms of percentages of correct responses. The percentages are collapsed across cueing conditions since that factor was not found to be significant $[F(1,14)=1.22, p>.05]$. Analyses of variance yielded $3 \%$ as an estimate of the standard error of the entries on Table 1. Temporal order recall was found to be superior to spatial order recall
$[F(1,14)=44.55, p<.01]$. The factor of serial position was found to be significant for both temporal and spatial positions [for temporal positions, $F(3,42)=$ $31.43, p<.01$; for spatial positions, $F(3,42)=8.10$, $p<.01]$; however the serial position functions were different in the two cases. In both temporal and spatial order recall, concave-upward bowed serial position curves, similar to those observed in previous studies (e.g., Healy, in press), occurred for temporal positions, whereas concave-downward curves occurred for spatial positions.

\section{DISCUSSION}

Recall of temporal and spatial order were compared in the present situation where the temporal and spatial positions of the to-be-recalled items were varied independently. The results support the notion that the serial position curves typically observed in short-term recall experiments arise as a consequence of temporal factors intrinsically involved in the maintenance of order information in memory. More specifically, the results are consistent with the predictions of the synchrony model.

However, there is an alternative explanation for the observed superiority of temporal order recall in terms of an asymmetry in the task. It can be argued that in both temporal and spatial order recall the subject's task was, in effect, to learn a list of paired associates; each of the four consonants had to be associated with its respective serial position. In temporal order recall, the subject was always given the four serial positions in a constant order-1, $2,3,4$-whereas in spatial order recall neither the four consonants nor the four serial positions were given in a constant order. For that reason, the present experiment may not provide an adequate comparison of temporal and spatial order recall. This criticism can be levelled equally against the previous experiments comparing temporal and spatial order retention (e.g., Lundberg \& Book, 1969, Mandler \& Anderson, 1971). A set 'of follow-up experiments (Healy, 1973) was designed to overcome this problem.

\section{REFERENCES}

Bjork, E. L., \& Healy, A. F. Short-term order and item retention. Journal of Verbal Learning and Verbal Behavior, 1974, 13, 80-97.

Estes, W. K. An associative basis for coding and organization in memory. In A. W. Melton \& E. Martin (Eds.), Coding processes in human memory. Washington, D.C: Winston, processes in hur

Healy, A. F. Short-term memory for temporal and spatial order information. Unpublished doctoral dissertation, Rockefeller University, 1973.

Healy, A. F. Separating item from order information in short-term memory. Journal of Verbal Learning and Verbal Behavior, in press.

Lundberg, I., \& Book, A. Postcued recall of competing spatial and temporal order. Umea Psychological Reports, 1969, No. 7.

Mandler, G., \& Anderson, R. Temporal and spatial cues in seriation. Journal of Experimental Psychology, 1971, 90, 128-135.

Murdock, B. B., Jr. Where or when: Modality effects as a function of temporal and spatial distribution of information. Journal of Verbal Learning and Verbal Behavior, 1969, 8, 378-383.

Slamecka, N. J. Serial learning and order information. Journal of Experimental Psychology, 1967, 74, 62-66.

(Received for publication September 27, 1974.) 